\title{
Carbon epoxy front hood for an electrical city vehicle
}

\author{
Paul Bere ${ }^{1}$, Calin Neamtu $^{2,}$, Mircea Dudescu ${ }^{3}$, Radu Comes $^{2}$ and Sergiu Solcan ${ }^{2}$ \\ ${ }^{1}$ Technical University of Cluj-Napoca, Manufacturing Engineering, Bd. Muncii 103-105, Romania \\ 2 Technical University of Cluj-Napoca, Design Engineering and Robotics, Bd. Muncii 103-105, \\ Romania \\ ${ }^{3}$ Technical University of Cluj-Napoca, Mechanical Engineering Department, Bd. Muncii 103-105, \\ Romania
}

\begin{abstract}
In the last decade fiber-reinforced polymer (FRP) had a very impressive development. Due to its physical and mechanical properties, this material is used in many high-end domains such as: aerospace, aviation, automotive, medical, engineering or building constructions. In the last period FRP are being intensely used in the automotive industry especially for the chassis manufacturing and other vehicle structural components. In this paper, the authors present the model of a carbon epoxy front hood of a two-passenger electrical car which is specially designed in urban area and which makes use of advanced FRP manufacturing.
\end{abstract}

\section{Introduction}

In recent decades, there have been significant changes in the use of materials in different fields across the world. Fiber reinforced polymer composite (FRP) materials represent a unique category of advanced materials with an outstanding scientific and industrial interest.

Today, major manufacturing companies are switching from traditional thermal-electric cars to electric one. Analysis predicts that the total cost of ownership of electric cars will dip below those with internal combustion engines in 2022. Electric cars are mostly intended to be used in the urban environment and the electric car research is focused on improving the deficiencies of the current vehicle systems. The use of composite materials in the construction process of the electric road vehicles will have a major impact to decisively reduce the mass of the car in order to reduce the energy consumption while also offer possibilities to increase the autonomy of the car.

Different researchers presented the current problems that may occur due to the use of these materials [1-3]. Whether it is constituents, micro or macro mechanics, theory of breakage of these materials, mechanical behavior, or general notions about the technology of obtaining them, these researchers have approached these subjects. The authors aim to achieve the best performance in terms of weight, global material cost and the best stiffness.

Different structures of reinforced composite materials are presented in the work of [48]. These researches are focused on either the mechanical characteristics or on reducing

\footnotetext{
*Corresponding author: calin.neamtu@muri.utcluj.ro
} 
their mass by using hybrid solutions of sandwich structures. The applications of these materials in the automotive field create the prerequisites for obtaining complex structures that have superior characteristics to the traditional materials regarding their mass reduction. The material behavior under high temperature conditions of composite materials is different from that of traditional materials. This is influenced by the type of matrix and the thermal treatment applied to its polymerization [9-13].

Today the manufacturers and designers of composite material products are not addressing the problem correctly at the design stage. They try to reproduce metal parts and make them from composite materials which represent a totally uninspired approach that greatly reduces the composite materials benefits. This approach is known as "Black Metal Pieces" and the result is a black carbon fiber piece made in the same shape as the metal parts. This approach doesn't make use of the composite material benefits, thus, there is a need to implement a new concept from the product design phase, namely the specific design of the composite parts.

In this paper, the authors present the design problems of creating a front hood for a small electric car designed for urban traffic. Starting from the typical static loads cases presented in the literature to determine the hood stiffness, the authors propose innovative solutions for the development of the material and its structure. In the case of a carbon fiber / epoxy reinforced composite material, the hood becomes stiffer using a sandwich structure. The ANSYS Workbench software solutions [14] are used to model the composite material architecture and to evaluate the stiffness behavior of the part.

\section{E-car concept 96BG}

The 96BG concept represents a small electric car designed to run in crowded cities. The car is intended to be used for various day-to-day activities within the city and it has four seats in order to accommodate a wide range of users. Design of the car is illustrated in Figure 1 and is adopted for the FRP material solutions.
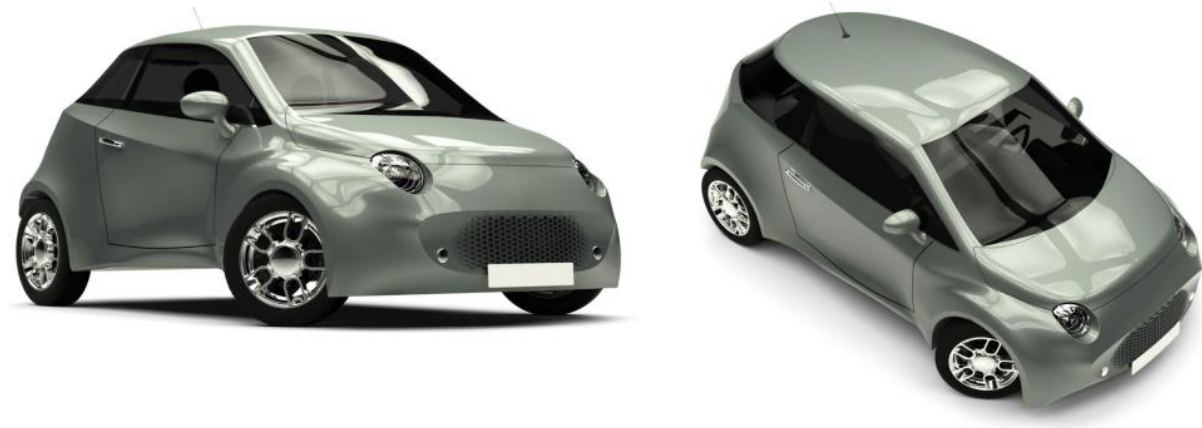

Fig. 1. E-car concept 96BG.

Figure 2 presents the designing procedure of the classic metal hood (on top of the figure) and the composite developed hood (on the bottom of the figure). For the composite hood, the ribs reinforcements on the back side used in the metallic design are eliminated and they are replaced by a composite structure.

The border of the hood is a like a frame that continues with an inner area having a different layup of the composite structure, in order to increase the stiffness of the hood without adding some separate glued parts. The cross-sectional view of the hood made of carbon/epoxy with respect to a Cartesian system is presented in the Figure 3. that illustrates the above described concept of the composite architectural layout. 


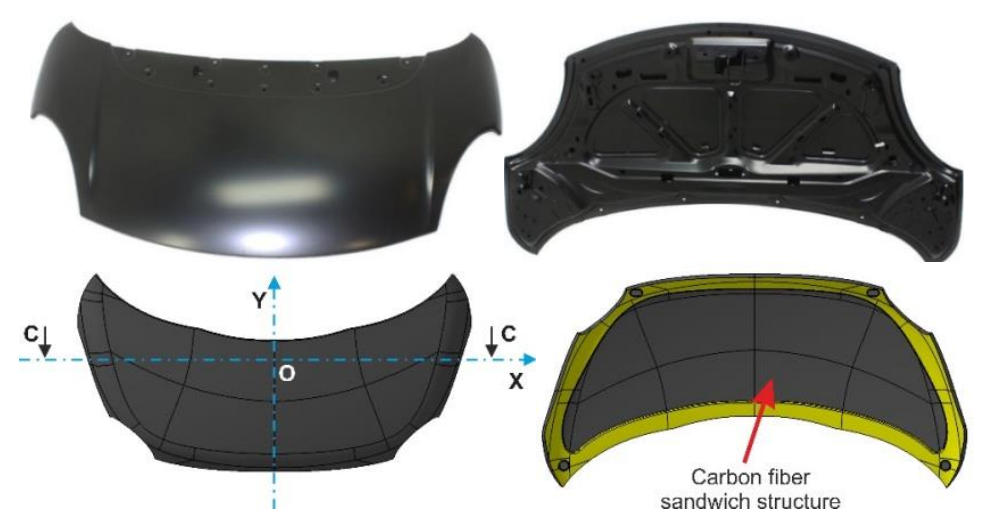

Fig. 2. Front hood design: up sheet metal, down FPR.

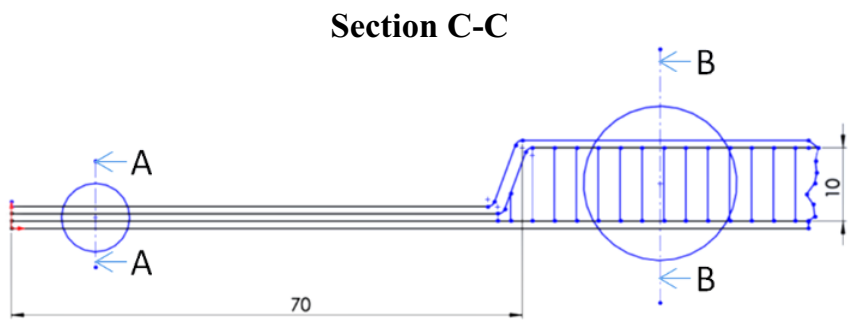

Fig. 3. Section view of the layers on the $\mathrm{X}$ axis.

\section{FRP material designs}

The edge of the car hood consists of three types of laminated structure along a length of 70 $\mathrm{mm}$. The laminated structures architectural layout is illustrated in detail in the A-A section. In the Figure 4 are presented the layers distribution of the proposal composite laminates. For the composite laminate denoted with 1 in Figure 4, the following architectural layers were chosen: [90/0 $\left.\pm 45_{2} / 90 / 0\right]$. For a $0 / 90$ ply a Twill structure type of $200 \mathrm{~g} / \mathrm{m}^{2}$ with a 0.25 $\mathrm{mm}$ thickness/layer and for the \pm 45 a biaxial fabric of $300 \mathrm{~g} / \mathrm{m}^{2}$ with a thickness of 0.3 $\mathrm{mm} /$ layer have been used. Another possible architectural arrangement for laminate denoted by 1 could be the following: [90/0 $\pm 452 / 90 / 0]$. For both $0 / 90$ and \pm 45 plies a Plain fabric of $90 \mathrm{~g} / \mathrm{m}^{2}$ of $0.1 \mathrm{~mm}$ thickness / layer was used and these layers are the first one arranged in the die and they represent the outer part of the bonnet.

On the interior, both on the border and the entire circumference of the bonnet the layers denoted in Figure 4.a. by 2 is applied. The layers configuration is: [ $\pm 45 / 0-902 / \pm 45]$. For the stratified layer denoted 3 in the Figure 4.a.-b., the following architectural layout was used: $[ \pm 45 / 0-90]$. For the $0 / 90$ a Twill type of $200 \mathrm{~g} / \mathrm{m}^{2}$ of $0.25 \mathrm{~mm}$ thickness/layer was used and for the \pm 45 ply a biaxial fabric of $300 \mathrm{~g} / \mathrm{m}^{2}$ with a thickness of $0.3 \mathrm{~mm} /$ layer. Another architectural arrangement for layers denoted by 3 could be: [90/0 $\pm 45 / 90 / 0]$. For $0 / 90$ and \pm 45 plies a plain fabric of $90 \mathrm{~g} / \mathrm{m}^{2}$ with $0.1 \mathrm{~mm}$ thickness was chosen.

In Figure 4.b. a detail is presented for the center of the sandwich structure of the bonnet. The laminated marked as 1 and 3 remain unchanged, and for layer 4 a Nomex honey comb with a thickness (height) of $10 \mathrm{~mm}$ and a diameter of $5 \mathrm{~mm}$ is used. For the points of interest (fastening of the hinges, the fasteners, and the support points, layers were superimposed by the biaxial fabric of $300 \mathrm{~g} / \mathrm{m}^{2}, 8$ layers, in this area the sandwich structure was eliminated. 


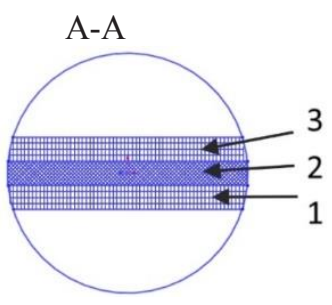

a.

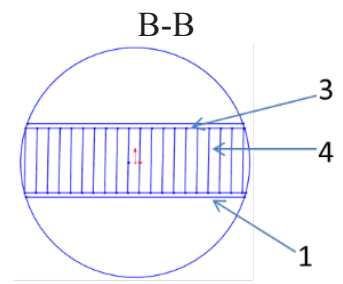

b.

Fig. 4. Details of the composite layers.

The staking sequence of the layers and the type of the reinforcement layers are selected to ensure a balanced structure to have on X-Y direction closed mechanical coefficients. In the same time, the proposed laminate is selected to avoid the material contraction in different directions. The fibers are applying to $0-90^{\circ}$ and $\pm 45^{\circ}$.

\section{Numerical simulations}

The finite element model contains all geometrical components of the above described hood. The simulation was realized using ANSYS Workbench software and the ACP tool for layup modelling of the composite materials. The composite material used in the simulation was defined as in the manufacturing process. The orthotropic material proprieties of the fabric epoxy carbon woven being those provided by the software material database (Epoxy Carbon Woven (230 GPa prepreg). The two analyzed cases differ only in stacking sequences and their thickness for the layer 1 and 3 as presented in figure 3 . The shell elements are used where the number of the elements was 2800 . The bases for the analysis are the established static load cases [15-18] to determine the longitudinal, transversal and torsional stiffness. The hood is bended in cases of the lateral and transversal stiffness tests and distorted in the torsional stiffness test. The loads are applied in vertical direction and have for each load case the intensities shown in Fig. 5.

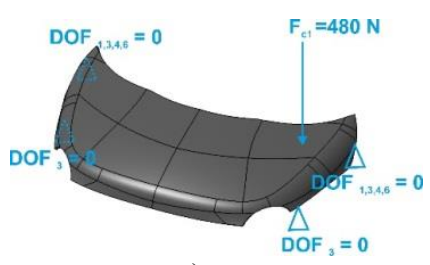

a)

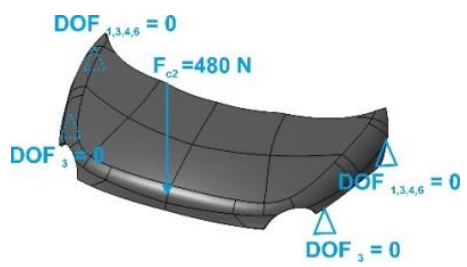

b)

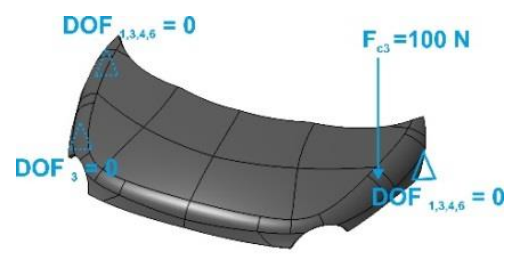

c)

Fig. 5. Load cases for: a) lateral stiffness, b) transversal stiffness and c) torsional stiffness.

In all three tests, the hood is mounted in design position and constrained in the supporting points, the hinges in the rear hood area and the buffer points in the front area, respectively. The assessment criterion is the total deflection of the load application point on 
the outer panel. Fig. 6 presents the total displacement distribution for investigated load cases.

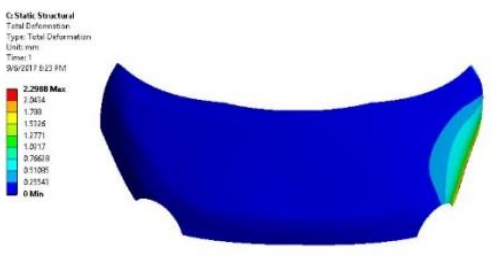

a)
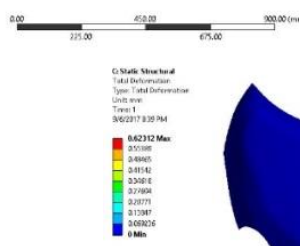

c)

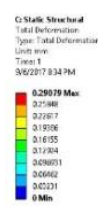

b)
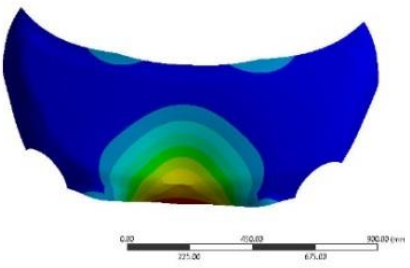
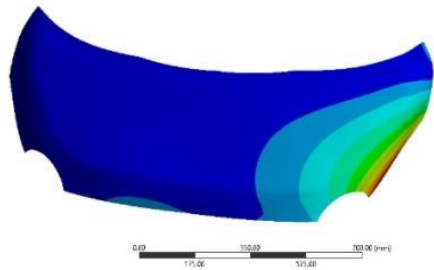

Fig. 6. Displacement distribution along the force direction obtained for first composite lay-up: a) lateral stiffness, b) transversal stiffness and c) torsional stiffness.

The obtained values give an indication about the hood stiffness in comparison with a similar one made from steel and ensure in this stage the proper composite and structural design. The stiffness results for these three cases of material are presented in table 1 .

Table 1. The numerical stiffness of the hood in case of different materials.

\begin{tabular}{|c|c|c|c|c|}
\hline $\begin{array}{c}\text { Stiffness K=F/ } \\
{[\mathbf{N} / \mathbf{m m}]}\end{array}$ & $\begin{array}{c}\text { Lateral } \\
{[\mathbf{N} / \mathbf{m m}]}\end{array}$ & $\begin{array}{c}\text { Transversal } \\
{[\mathbf{N} / \mathbf{m m}]}\end{array}$ & $\begin{array}{c}\text { Torsional } \\
{[\mathbf{N} / \mathbf{m m}]}\end{array}$ & $\begin{array}{c}\text { Mass } \\
{[\mathbf{k g}]}\end{array}$ \\
\hline Case I Carbon layers by Twill $\mathbf{2 0 0 g} / \mathbf{m}^{\mathbf{2}}$ & 209,6 & 1655,1 & 160,5 & 2,38 \\
\hline Case II Carbon layers by Plain $\mathbf{9 0 g} / \mathbf{m}^{\mathbf{2}}$ & 80,1 & 861,3 & 66,6 & 1,41 \\
\hline Case III from Steel & 39,5 & 406,9 & 23 & 5,6 \\
\hline
\end{tabular}

A similar steel hood (Figure 7) made of structural steel sheets of $0.5 \mathrm{~mm}$ thickness, has been investigated to check and validate if the of the proposed design of the composite structure is a proper one in terms of strength and stiffness.

a)

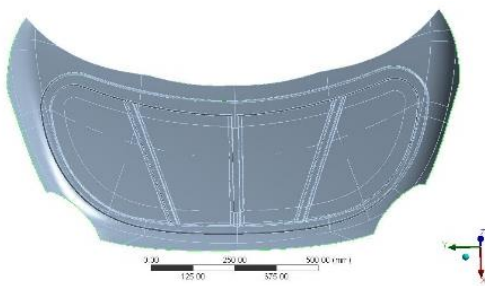

b)

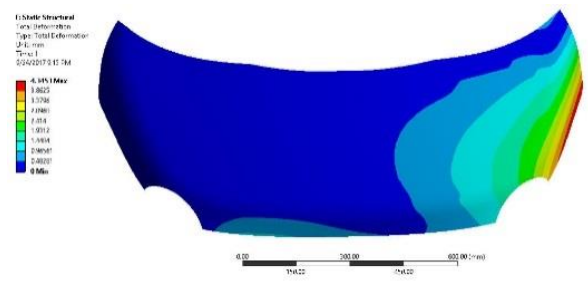

Fig. 7. Simplified steel structure of the hood: a) geometry and b) displacement distribution along the force direction for the load case torsional stiffness.

Comparison between experimental and numerical stiffness of the structure is necessary to be performed in the next step and consists future work.

Comparatively with the stiffness values calculated for a similar steel hood (lateral $39.5 \mathrm{~N} / \mathrm{mm}$; transversal $-406.9 \mathrm{~N} / \mathrm{mm}$ and torsional $-23 \mathrm{~N} / \mathrm{mm}$ ) we obtained higher values even for the lighter structure containing Plain fabric with $90 \mathrm{~g} / \mathrm{m}^{2}$ (lateral $-80.1 \mathrm{~N} / \mathrm{mm}$; 
transversal - $861 \mathrm{~N} / \mathrm{mm}$ and torsional $-67 \mathrm{~N} / \mathrm{mm}$ ). Thus, the composite structure proved to be two times minimum stiffer than the steel structure.

\section{Conclusions}

For the analyzed hood having different composite structural design (Twill $200 \mathrm{~g} / \mathrm{m}^{2}$ vs. Plain $90 \mathrm{~g} / \mathrm{m}^{2}$ ), a decrease in lateral stiffness of $60 \%$, in transversal stiffness of $45 \%$ and in torsional stiffness of $56 \%$ was obtained. If we analyses the weight of the hood in the two cases we obtained a decrease of $41 \%$. The mass decrease of 2.4 times comparing with the steel hood. The first structure Twill $200 \mathrm{~g} / \mathrm{m}^{2}$ is stiffer compared to the second one (Plain $90 \mathrm{~g} / \mathrm{m}^{2}$ ), for both cases the obtained stiffness values are higher than the stiffness of a similar steel hood. This validates the proposed architecture of the composite material designed to fabricate a light structure of a car bonnet. The front hood solution adopted is new and specific for FRP design. Both configuration layers studied have been numerically analyzed under typical loads in order to determine the lateral, transversal and torsional stiffness.

This work was supported by a grant of the Romanian National Authority for Scientific Research and Innovation, CNCS/CCCDI-UEFISCDI, project number PN-III-P2-2.1-96BG-2016-0210, within PNCDI III.

\section{References}

1. Ch. Decolon, Structures composites, Hermes, Paris, (2000)

2. L.P. Kollar, G.S. Springer, Mechanics of Composite Structures, Springer, Cambridge, (2003)

3. I.A., Popan, A.I. Popan, Acta Tehnica Napocensis, 60, II, 251-254 (2017)

4. J. Zhang, K. Chaisombat, el al, Materials and Design 36, 75-80 (2012)

5. P. Beardmore, C.F. Johnson, Compos Sci Technol, 26, 251-81 (1986)

6. H.A. Al-Qureshi, J. Mater Process Technol, 118, 58-61 (2001)

7. P. Hreha, A. Radvanska, et al, Metrol. Meas. Syst., 22(2), 315-326 (2015)

8. N.F. Betzler, C. Slater, M. Strangwood, Sports Eng., 14(1), 27-37 (2011)

9. Y.I. Tsai, E.J. Bosze, et al., Compos Sci Technol, 69(3-4), $432-437$ (2009)

10. P.J. Liotier, A. Vautrin, J.M. Beraud, Compos A Appl Sci Manuf, 42(4), 425-437 (2011)

11. G.M. Krolczyk, P. Nieslony, Krolczyk J.B., Samardzic I., Legutko S., Hloch S., Barrans S., R.W. Maruda, J. Measurement, 70, 203-213 (2015)

12. I.A. Popan, N. Balc, A.I. Popan, MSE, MATEC Web Conf., 121 (2017)

13. E.C. Botelho, L.C. Pardini, M.C. Rezende, J Mater Sci., 41(21) (2006)

14. ANSYS Workbench, Release 16.0, ANSYS, Inc., Canonsburg, USA (2015)

15. M. Hamacher, R. Wohlecker, L. Ickert, Abaqus Users' Conference, May 19-22, Newport, Rhode Island, USA, 1-16 (2008)

16. C.E. Torricelli, L. Splendi and M. Pettazzoni, in Proceedings of the World Congress on Engineering WCE 2011, July 6 - 8, London, U.K (2011)

17. N. Bhaskar, P. Rayudu, International Journal of Current Engineering and Technology, 5 (2015)

18. S. M. Darwish, S. M. Elseufy, A. Ahmad, Journal of Management \& Engineering Integration, 7(62) (2014) 